\title{
Brain structural and functional correlates of resilience to Bipolar Disorder
}

\author{
Sophia Frangou* \\ Department of Psychosis Studies, Section of Neurobiology of Psychosis, Institute of Psychiatry, King's College London, London, UK
}

\section{Edited by:}

João R. M. Oliveira, Federal

University of Pernambuco, Brazil

Reviewed by:

João R. M. Oliveira, Federal

University of Pernambuco, Brazil

Jonas Hannestad, Yale School of

Medicine, USA

*Correspondence:

Sophia Frangou, Department of

Psychosis Studies, Section of

Neurobiology of Psychosis,

Institute of Psychiatry, King's

College London, De Crespigny Park,

London SE5 8AF, UK

e-mail: sophia.frangou@kcl.ac.uk

\begin{abstract}
Background: Resilient adaptation can be construed in different ways, but as used here it refers to adaptive brain responses associated with avoidance of psychopathology despite expressed genetic predisposition to Bipolar Disorder (BD). Although family history of $\mathrm{BD}$ is associated with elevated risk of affective morbidity a significant proportion of first-degree relatives remain free of psychopathology. Examination of brain structure and function in these individuals may inform on adaptive responses that pre-empt disease expression. Methods: Data presented here are derived from the Vulnerability to Bipolar Disorders Study (VIBES) which includes BD patients, asymptomatic relatives and controls. Participants underwent extensive investigations including brain structural (sMRI) and functional magnetic resonance imaging (fMRI). We present results from sMRI voxel-based-morphometry and from conventional and connectivity analyses of fMRI data obtained during the Stroop Colour Word Test (SCWT), a task of cognitive control during conflict resolution. All analyses were implemented using Statistical Parametric Mapping software version 5 (SPM5). Resilience in relatives was operationalized as the lifetime absence of clinical-range symptoms. Results: Resilient relatives of BD patients expressed structural, functional, and connectivity changes reflecting the effect of genetic risk on the brain. These included increased insular volume, decreased activation within the posterior and inferior parietal regions involved in selective attention during the SCWT, and reduced fronto-insular and fronto-cingulate connectivity. Resilience was associated with increased cerebellar vermal volume and enhanced functional coupling between the dorsal and the ventral prefrontal cortex during the SCWT. Conclusions: Our findings suggests the presence of biological mechanisms associated with resilient adaptation of brain networks and pave the way for the identification of outcome-specific trajectories given a bipolar genotype.
\end{abstract}

Keywords: MRI, bipolar disorder, connectivity, predisposition, risk, resilience

\section{INTRODUCTION}

Bipolar Disorder (BD) is characterized by mood dysregulation manifesting as recurrent episodes of depression and mania with variable inter-episode remission (APA, 1994). Genetic factors are known to contribute between $60 \%$ and $85 \%$ to the liability to BD (McGuffin et al., 2003; Lichtenstein et al., 2009). However, the pathway leading from genetic risk to clinical phenotype is complex and not clearly mapped. Recent genome-wide association studies have identified a number of risk conferring loci (Ferreira et al., 2008; Sklar et al., 2011). These however, explain only a small fraction of the heritability to $\mathrm{BD}$. Genetic proximity to affected individuals remains the single most significant predictor of disease expression as first-degree relatives of patients show a 10-fold increase in their relative risk for BD (Smoller and Finn, 2003). This observation often obscures the fact that the majority (approximately 60\%) of first-degree relatives of $\mathrm{BD}$ patients remain free of psychiatric pathology (Mowbray et al., 2006). Consequently research to date has focused nearly exclusively on risk-increasing factors without similar attention being directed to factors associated with resilience. This paper attempts to address this issue within the framework of resilient adaptation.
Resilient adaptation can be construed in different ways, but as used here it refers to adaptive brain features associated with avoidance of psychopathology despite expressed genetic predisposition to $\mathrm{BD}$. There are several considerations that led us to this particular formulation. Firstly, we employed an operational definition of resilience (Carpenter et al., 2001) predicated on the lifetime absence of "adverse" clinical outcomes (i.e., clinicalrange symptoms). There is substantial evidence of an association between genetic risk for $\mathrm{BD}$ and changes in cognition (Arts et al., 2008; Bora et al., 2009; Glahn et al., 2010), brain structure (McDonald et al., 2004; McIntosh et al., 2004) and brain function (Drapier et al., 2008; Thermenos et al., 2010). Abnormalities in these measures could also be considered as "adverse" outcomes. However, we chose to define outcome using clinical symptoms only since our primary concern is to determine the correlates of resilience to overt disease expression. Secondly, the variance in risk among first-degree relatives of BD patients is expected be a large. Moreover, it is currently not possible to define the specific risk factors that comprise each individual's genetic predisposition. Here we follow the convention of using genetic proximity to an affected individual as a measure of "genetic" 
burden. Despite encompassing individuals with variable genetic liability this approach has been successfully employed in nearly all studies that have examined the impact of genetic risk for $\mathrm{BD}$ (e.g., McDonald et al., 2004; McIntosh et al., 2004; Arts et al., 2008; Drapier et al., 2008; Thermenos et al., 2010). Thirdly, an added difficulty arises when considering the potential contribution of shared "non-genetic" factors to disease liability amongst family members. To minimize the effects of shared environment the unaffected family members sampled here were unrelated to each other. Fourthly, resilience is likely to arise from adaptive responses at multiple levels ranging from cellular (Hunsberger et al., 2009) to psychological (Galvez et al., 2011). Here we focus exclusively on the brain structural and functional correlates of resilience as assessed with MRI. As BD is thought to arise from disruptive changes in brain systems (Phillips et al., 2008) the question is whether adaptive changes may promote resilience. Fifthly, our definition requires the presence of brain structural and functional deviance in relatives indicative of expressed genetic predisposition as a means of distinguishing between apparent and true resilience. Apparent resilience may be a consequence of low genetic "burden" in which case disruption to brain systems in healthy relatives would be expected to be minimal. The presence of brain structural and functional abnormalities that are common in healthy relatives and in BD patients is considered as evidence of expressed shared genetic predisposition. Obviously, such abnormalities define a state of vulnerability to BD but are not sufficient for disease expression. Sixthly, brain structural and functional features that differentiate healthy relatives from BD patients and controls are considered as adaptive responses to abnormalities related to genetic predisposition. Seventhly, the diagnostic status of healthy relatives has the potential to change. Apparent resilience may be a function of the timing and length of the period of observation. The peak age of onset of $\mathrm{BD}$ is between 16 and 30 years (Merikangas et al., 2011). The majority of individuals who develop BD will do so before aged 25 years (Merikangas et al., 2011) whereas the conversion rate thereafter is very low (Akiskal et al., 1995; Coryell et al., 1995). Consequently we sampled healthy relatives that had passed through the highest period of risk for developing BD.

With these considerations in mind we examined the brain structural and functional correlates of resilience in healthy firstdegree relatives of patients with BD derived from the Vulnerability to Bipolar Disorders Study (VIBES) (Frangou, 2009). The functional paradigm employed was the Stroop Colour Word Test (SCWT) (Stroop, 1935), considered a prototypical task of cognitive control during conflict resolution. The SCWT tests the ability to overcome interference from competing sensory information (selective attention) and, in parallel, to choose the appropriate response amongst conflicting alternatives (inhibitory control). Disruption in these processes may be central to the pathophysiology of BD since distractibility and disinhibition are core diagnostic symptoms of mania (APA, 1994). Additionally, neurocognitive studies have reliably shown that abnormalities in selective attention and inhibitory control persist in remitted patients (Arts et al., 2008; Bora et al., 2009; Stefanopoulou et al., 2009).

Versions of the SCWT have been successfully used in functional magnetic resonance imaging (fMRI) studies to highlight deficits in $\mathrm{BD}$, particularly within the ventrolateral prefrontal cortex (VLPFC) (Blumberg et al., 2003; Gruber et al., 2004; Malhi et al., 2005; Kronhaus et al., 2006; Roth et al., 2006; Lagopoulos and Malhi, 2007; Pavuluri et al., 2008; Chen et al., 2011; Pompei et al., 2011a,b). Additional functional deficits in patients with BD during this task have been noted in the dorsolateral prefrontal cortex (DLPFC), (Kronhaus et al., 2006; Lagopoulos and Malhi, 2007), the anterior cingulate cortex (ACC) (Strakowski et al., 2005; Roth et al., 2006) and in subcortical regions (Blumberg et al., 2003; Malhi et al., 2005; Strakowski et al., 2005).

We tested the following hypotheses: (a) healthy relatives and $\mathrm{BD}$ patients will share brain structural and functional features that will differentiate both groups from controls. These biological features will be considered as expressed genetic predisposition to $\mathrm{BD}$, (b) healthy relatives will manifest brain structural and functional features differentiating them from $\mathrm{BD}$ patients and controls. These biological features will be considered as adaptive responses associated with resilience, and (c) BD patients will show brain structural and functional changes differentiating them from healthy relatives and controls. These changes will be considered as correlates of disease expression. The value of this approach is threefold: (a) it enables disambiguation between biological alterations relating to genetic risk for $\mathrm{BD}$ that may be necessary but not sufficient for the development of overt clinical symptoms, (b) it focuses attention on dynamic biological processes engaged in overcoming genetic predisposition to $\mathrm{BD}$, and (c) it has the potential to identify mechanisms that offer new insights for the prevention or treatment of $\mathrm{BD}$.

\section{MATERIALS AND METHODS PARTICIPANTS}

All participants (Table 1) derived from the VIBES study sample (Frangou, 2009; Kempton et al., 2009; Walterfang et al., 2009; Takahashi et al., 2010; Jogia et al., 2011; Lelli-Chiesa et al., 2011; Perrier et al., 2011; Pompei et al., 2011a,b). Patients fulfilled criteria for BD type I according to the Diagnostic and Statistical Manual of Mental Disorders, 4th edition, revised (DSM-IV) (APA, 1994), had no comorbid psychiatric disorders and no family history (up to second-degree) of schizophrenia or schizophrenia spectrum disorders. Siblings and offspring without a personal history of Bipolar Spectrum Disorders were also invited to participate. Healthy controls without a personal or family history of any Axis I DSM-IV disorders were selected to match

Table 1 | VIBES sample: clinical and demographic characteristics.

\begin{tabular}{llll}
\hline & $\begin{array}{l}\text { Bipolar patients } \\
(\boldsymbol{n}=\mathbf{4 7})\end{array}$ & $\begin{array}{l}\text { Relatives } \\
(\boldsymbol{n}=\mathbf{4 8})\end{array}$ & $\begin{array}{l}\text { Controls } \\
(\boldsymbol{n}=\mathbf{7 1})\end{array}$ \\
\hline Age & $46.2(11.5)$ & $36.5(13.8)$ & $39.8(15.3)$ \\
Gender (female/male) & $26 / 21$ & $25 / 25$ & $35 / 36$ \\
IO & $118.7(17.7)$ & $117.8(16.8)$ & $121.5(19.3)$ \\
Age of onset & $25.5(8.2)$ & $\mathrm{N} / \mathrm{A}$ & $\mathrm{N} / \mathrm{A}$ \\
IIIness duration & $20.0(9.1)$ & $\mathrm{N} / \mathrm{A}$ & $\mathrm{N} / \mathrm{A}$ \\
HDRS & $3.0(3.9)$ & $0.0(0.3)$ & $(0.2)(0.5)$ \\
YMRS & $1.3(2.9)$ & $0.0(0)$ & $(0.2)(0.5)$ \\
BPRS & $26.9(3.5)$ & $24.0(0.3)$ & $24.4(0.6)$
\end{tabular}


patients and relatives in age, sex, and educational level. All participants were screened to exclude past, current, and hereditary neurological disorders, DSM-IV lifetime substance dependence or abuse in the preceding six months and contraindications to MR imaging.

\section{ASSESSMENTS}

All participants underwent detailed interview and assessment. Diagnostic status was ascertained using the Structured Clinical Interview for DSM-IV for Axis I (First et al., 2002a,b) and Axis II diagnoses (First et al., 1997). Family history of psychiatric disorders was ascertained using the Family Interview for Genetic Studies (Maxwell, 1992). Symptoms were evaluated with the Hamilton Depression Rating Scale (HDRS) (Hamilton, 1960), the Young Mania Rating Scale (YMRS) (Young et al., 1978) and the Brief Psychiatric Rating Scale (BPRS) (Lukoff et al., 1986). The intelligence quotient (IQ) derived from the Wechsler Adult Intelligence Scale-Revised (WAIS-R) (Wechsler, 1997) was used as a measure of general intellectual ability. Handedness was based on self-report. Prior to scanning BD patients were assessed weekly over a minimum period of one month to ensure that at each evaluation they (a) scored below seven in the HDRS and YMRS and (b) there had been no change to their medication status.

There were no differences between groups in sex $(p=0.95)$, age $(p=0.23)$, and IQ $(p=0.52)$. Although the level of symptomatology was very low in all groups (Table 1), BD patients had higher HDRS, YMRS, and BPRS scores compared to all other groups (all $p<0.003$ ) while there was no difference between relatives and controls (all $p>0.80$ ).

None of the relatives was on prescribed medication. Thirtynine $\mathrm{BD}$ patients were on psychotropic medication; 17 on antipsychotics (12 on atypical, two on typical and three on both), 30 on mood stabilizers (17 on lithium, four on lamotrigine, three on carbamazepine and 10 on sodium valproate), and 13 on selective serotonin reuptake inhibitors. None received anticholinergic or benzodiazepines. The comparable daily dose was calculated for current antipsychotic use when relevant (Bezchlibnyk-Butler and Jeffries, 2000). Unmedicated BD patients had discontinued medication of their own accord for an average of six months. Medicated and unmedicated BD patients did not differ in age of onset, illness duration, IQ, HDRS, and YMRS total scores (all $p>0.31)$.

\section{NEUROIMAGING}

Both anatomical and functional imaging data were acquired during the same session using a 1.5T GE Neuro-optimized Signa Magnetic resonance (MR) system (General Electric, Milwaukee, WI) based at the Maudsley Hospital, London. All images were first checked for gross structural anomalies and were then processed and analyzed using Statistical Parametric Mapping software version 5 (SPM5) (www.fil.ion.ucl.ac.uk/spm/software/spm5) in a Matlab environment (Version 7, The Mathworks Inc, Natick, MA).

\section{Structural MRI}

Anatomical images were acquired in the axial plane using a $\mathrm{T}_{1}$-weighted, three-dimensional (3D) $3 \mathrm{D}$ inversion recovery prepared spoiled gradient recalled protocol [echo time
$(\mathrm{TE})=5.1 \mathrm{~ms}$, repetition time $(\mathrm{TR})=1800 \mathrm{~ms}$, inversion time $=450 \mathrm{~ms}$, flip angle $=20^{\circ}$, slice thickness $=1.5 \mathrm{~mm}$, in plane resolution $=0.9375 \times 0.9375 \mathrm{~mm}$, matrix size $=256 \times 192$, field of view $=40 \times 180 \mathrm{~mm}$, number of excitations $=1]$.

We implemented voxel-based morphometry (VBM) using unified segmentation in SPM. Images were transformed into standard stereotactic Montreal Neurological Institute (MNI) space and smoothed using a Gaussian isotropic kernel of $12 \mathrm{~mm}$ full width half maximum (FWHM). The gray, white, and CSF fractions of the modulated images were summed to produce an estimate of total intracranial volume (TIV). There was no significant difference in mean TIV between the groups $(p=0.15)$. The mean TIV of the relatives was higher by $3.6 \%$ and $4.5 \%$, respectively, compared to that of controls and $\mathrm{BD}$ patients, and therefore, TIV was included as a covariate in an analysis of covariance (ANCOVA) model in SPM to examine the effect of group (BD patients, relatives, controls) on regional gray matter volume. The threshold for statistical significance was set at $p<$ 0.001 (uncorrected) (Thirion et al., 2007) with a cluster threshold of $=5$. We used MarsBaR (www.marsbar.sourceforge.net) to extract gray matter volumes from each subject from suprathreshold regions for further analyses implemented in SPSS 15.0 (SPSS Inc., Chicago, IL, USA) to examine the effect of medication.

\section{Functional MRI}

The SCWT was administered over six minutes using a block design incorporating alternating neutral (control) and interference (active) conditions. In the interference condition, stimuli were single color words (YELLOW, GREEN, RED, and BLUE) displayed in an incongruent font color (e.g., "GREEN" displayed in red font color). In the neutral condition a string of four Xs was displayed in one of the four font colors. There were five blocks of each condition, with 10 stimuli per block. Each stimulus was presented on a black background (duration $100 \mathrm{~ms}$ ), preceded by a fixation cross (duration $1500 \mathrm{~ms}$ ) and followed by a blank screen (duration $2100 \mathrm{~ms}$ ). Participants were instructed to ignore the word referent and name the font color. Their responses were recorded using voice activated software. Performance was evaluated in terms of response time and accuracy (\% correct responses).

A total of $104 \mathrm{~T} 2 *$-weighted echo planar imaging brain volumes depicting blood-oxygenation level-dependent (BOLD) contrast were acquired at each of 18 non-contiguous axial planes $(\mathrm{TE}=40 \mathrm{~ms}$, actual $\mathrm{TR}=3500 \mathrm{~ms}$, voxel dimensions $=3.75$ $\times 3.75 \times 7 \mathrm{~mm}$, interslice gap $=0.7 \mathrm{~mm}$, matrix size $=64 \times$ 64 , flip angle $=90^{\circ}$ ). Images were realigned, transformed into MNI space, and smoothed with an isotropic Gaussian kernel of $8 \mathrm{~mm}$ FWHM. Registration parameters were extracted and compared between groups. The first-level analysis was performed by modeling the fMRI responses using a canonical hemodynamic response function (HRF) convolved with the vectors of interest. We analyzed the data using a general linear model with the following vectors of onset as explanatory variables: correct responses in the incongruent condition, correct responses in the neutral condition, incorrect responses (errors of commission or omission). By modeling out errors, we focused on successful trials. Six movement parameter vectors (translation $x, y, z$, and rotation 
$x, y, z)$ generated from the realignment procedure were also modeled as regressors of no interest. The model additionally included drift terms up to $1 / 128 \mathrm{~Hz}$ to remove low-frequency components, and global confounds were removed using global normalization. Contrast images representing the incongruent minus neutral condition were produced for each subject. Full factorial analysis using a random-effects model was conducted to examine the effect of group with total BPRS score and age as covariates. Suprathreshold clusters were identified using a False Discovery Rate (FDR) correction of $p<0.05$. Weighted parameter estimates were extracted from each suprathreshold cluster and used in further analyses implemented in SPSS 15.0 (SPSS Inc., Chicago, IL, USA) to examine the effect of medication and relationship to performance.

Both for structural and functional MRI analyses stereotactic coordinates were converted from MNI spatial array to that of Talairach and Tournoux (www.mrc-cbu.cam.ac.uk/ Imaging/mnispace.html) and corresponding Brodmann areas (BA) were identified with the Talairach Daemon Client (www.talairach.org).

\section{Functional connectivity analysis}

Functional connectivity analysis was performed using Psychophysiological Interaction (PPI) (Friston et al., 1997) implemented in SPM5 and focused on the connectivity of the VLPFC (seed region) during the SCWT. The design matrix comprised three regressors: the "psychological variable," representing the experimental task (SCWT), the "physiological variable," representing the signal time course in the seed region, and a variable representing their interaction. In each individual the seed point was localized in native space based on the coordinates for the right VLPFC from the factorial group contrast for the incongruent $>$ neutral condition. A region of interest (ROI) was extracted from a sphere of $2 \mathrm{~mm}$ radius around the group maxima within the same anatomical area defined by the PickAtlas toolbox (Maldjian et al., 2003), and thresholded at $p<0.05$ uncorrected to ensure its presence in all subjects. A variable representing the interaction between each time series and the psychological variable (incongruent condition vs. neutral condition) was constructed for each subject. Voxel-wise PPI analysis was conducted within each group separately. Subject-specific contrast images were then entered into a random-effects analysis using one-sample $t$-tests (thresholded at $p<0.0001$ voxel-wise with $p<0.05$ cluster level correction). Group differences (BD patients, relatives, controls) in functional connectivity we examined the interaction between the PPI (interaction between VLPFC activity and SCWT) and group (thresholded at $p<0.001$ voxel-wise). No effect of medication was detected in in PPI analyses conducted $\mathrm{BD}$ patients.

\section{RESULTS}

\section{STRUCTURAL MRI}

BD patients and relatives showed similar structural changes in the left insula (BA13) $(x=44, y=40, z=19, Z$-score $=3.40$, cluster size $=17)$. Mean insula volume was significantly greater in BD patients $(p=0.008)$ and in relatives $(p=0.013)$ compared to controls (Figure 1). However, the volume of the vermis was uniquely increased in relatives compared to $\mathrm{BD}$ patients $(p=$ 0.005) and controls (all $p=0.004)$ (Figure 1).

\section{FUNCTIONAL MRI}

In the neutral and interference conditions controls' accuracy and reaction time were, respectively, 94.22 (8.90) and $0.51 \mathrm{~s}(0.28)$ and 92.66 (9.96) and $0.76(0.43)$. Patients had an accuracy of 93.42 (9.02) and reaction time of $0.52 \mathrm{~s}(0.28)$ in the neutral condition and an accuracy of 93.33 (7.58) and reaction time of $0.73 \mathrm{~s}(0.42)$ in the interference condition. Relatives had an accuracy of 98.76 (6.68) and reaction time of $0.51 \mathrm{~s}(0.14)$ in the neutral condition and an accuracy of 95.84 (7.35) and reaction type of $0.74 \mathrm{~s}(0.25)$ in the interference condition. There was no effect of group on accuracy $(p=0.46)$ or response time $(p=0.23)$ and no significant interactions between group and age, IQ, and BPRS score on any measure (all $p>0.14$ ).

Group differences in BOLD signal were observed in the superior parietal lobule (BA7) $(x=32, y=-58, z=43, Z=4.54$, cluster size $=290$ and $x=-20, y=-72, z=44, Z=4.41$, cluster size $=43)$, the inferior parietal lobule (BA40) $(x=34, y=$ $-48, z=41, Z=4.81$, cluster size $=189$ and $x=-42, y=-32$, $z=50, Z=4.60$, cluster size $=20$ ), the head of the caudate $(x=-2, y=10, z=1, Z=4.31$, cluster size $=19)$ and the VLPFC (inferior frontal gyrus; BA47) $(x=34, y=26, z=-8$, $Z=4.19$, cluster size $=30$ ).

In all these clusters, mean activation in $\mathrm{BD}$ patients was reduced compared to that of controls (all $p<0.03$ ). Relatives showed deficits in parietal engagement that were comparable to that of patients $(p>0.55)$ (Figure 1). However, the mean activation in the caudate and in the VLPFC in relatives was comparable to that of controls $(p>0.24)$ and significantly greater than that of BD patients $(p<0.02)$.

\section{CONNECTIVITY ANALYSIS}

During the SCWT controls showed significant positive interactions between the right VLPFC and the left caudate nucleus and parietal cortex. Negative interactions were found between the right VLPFC with the insula bilaterally, with the ventral ACC (vACC) on the left and with the globus pallidus on the rights (Table 2). In patients with BD the connectivity of the VLPFC was generally reduced within this network with the exception of the insula where abnormally positive connectivity was noted. In relatives, the connectivity of the VLPFC with the vACC and insula was reduced (Figure 1). However, the coupling of the VLPFC with parietal and striatal regions was preserved and there was evidence of additional connectivity between the VLPFC and the DLPFC (Figure 1).

\section{DISCUSSION}

We hypothesized that resilient relatives of $\mathrm{BD}$ patients would show unique brain structural and functional features that could reflect adaptive responses mitigating the effect of genetic predisposition. Our results suggest that resilience is associated with increased vermal volume and greater connectivity between the ventral and dorsal prefrontal cortex (PFC). The presence of brain structural and functional alterations that were common in relatives and patients suggests that resilience in relatives arises despite 


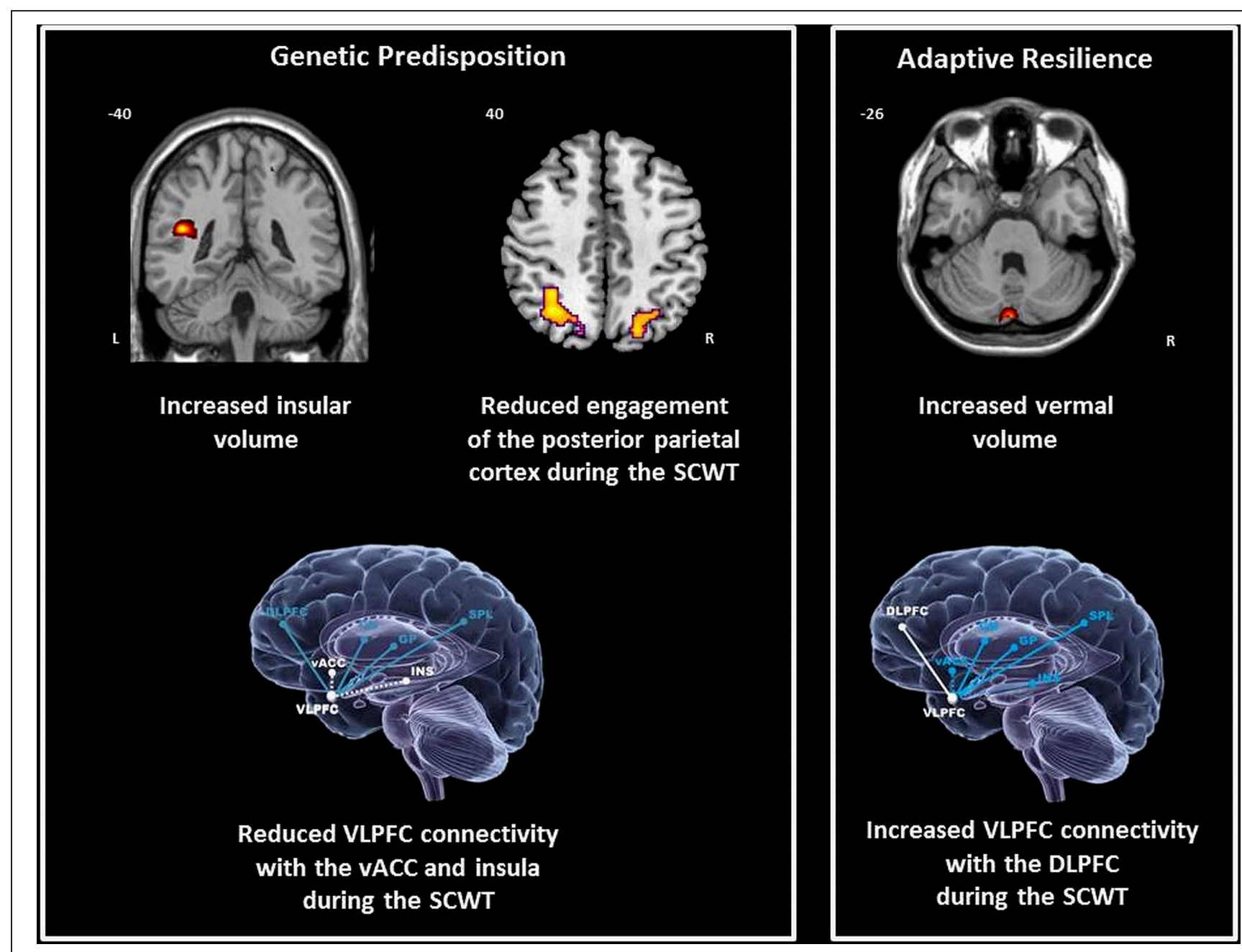

FIGURE 1 | Neural correlates of genetic predisposition and resilience in relatives of bipolar patients. $\mathrm{DLPFC}=$ dorsolateral prefrontal cortex; $\mathrm{CN}=$ caudate nucleus; $\mathrm{GP}=$ globus pallidus; Ins = insula; $\mathrm{SPL}=$ superior parietal cortex; VACC; ventral anterior cingulate cortex; VLPFC = ventrolateral prefrontal cortex; coordinates are presented in Talairach and Tournoux space $x=$ sagittal; $y=$ coronal; $z=$ axial. disruption in some brain systems mediated by shared genetic predisposition. The significance of the findings relating to genetic predisposition and disease expression in this sample has been discussed in detail in our previous publications (Kempton et al., 2009; Pompei et al., 2011a,b). Here we focus specifically on the correlates of resilience and their implications for BD.

\section{STRUCTURAL BRAIN CORRELATES OF RESILIENCE TO BD}

Relatives showed an increase in the volume of the vermis compared to patients and controls. This finding highlights the value of the resilience concept in identifying the contribution of brain regions that would not have been predicted by models of risk for disease expression. Cerebellar involvement is not a core feature of disease expression for BD (Kempton et al., 2008, 2011). Until recently, the cerebellum was mostly considered in terms of its contribution to motor control. However, has become apparent that it has a wider role in the regulation of autonomic function and cognition (Reis and Golanov, 1997; Parsons et al., 2000; Craig, 2002; Singer et al., 2004) as well as of affective processing
(Schmahmann and Caplan, 2006). In humans, cerebellar lesions give rise to a constellation of cognitive and affective abnormalities collectively referred to as the cerebellar cognitive affective syndrome (Schmahmann and Sherman, 1998). Based on fMRI data a functional distinction has been drawn between the anterior and posterior cerebellum; the former is more intimately involved with higher cognitive function while the latter, including the vermis, contributes mostly to affective regulation (Stoodley and Schmahmann, 2009, 2010). It is thought that the posterior cerebellum forms representation of internal affective and somatic states and, together with cortical regions, it implements adaptive responses to maintain "homeostatic" control (Schmahmann, 2004; Ramnani, 2006). Accordingly increased vermal volume in relatives could be interpreted as an adaptive response aimed at maintaining affective equilibrium.

As previously mentioned genetic predisposition to $\mathrm{BD}$ was associated with increased insular volume while increased vermal volume was only observed in resilient relatives. This raises questions as to how these two findings may relate to each other. 
Table 2 | Psychophysiological interactions with the right ventrolateral prefrontal cortex in BD patients, their relatives, and controls.

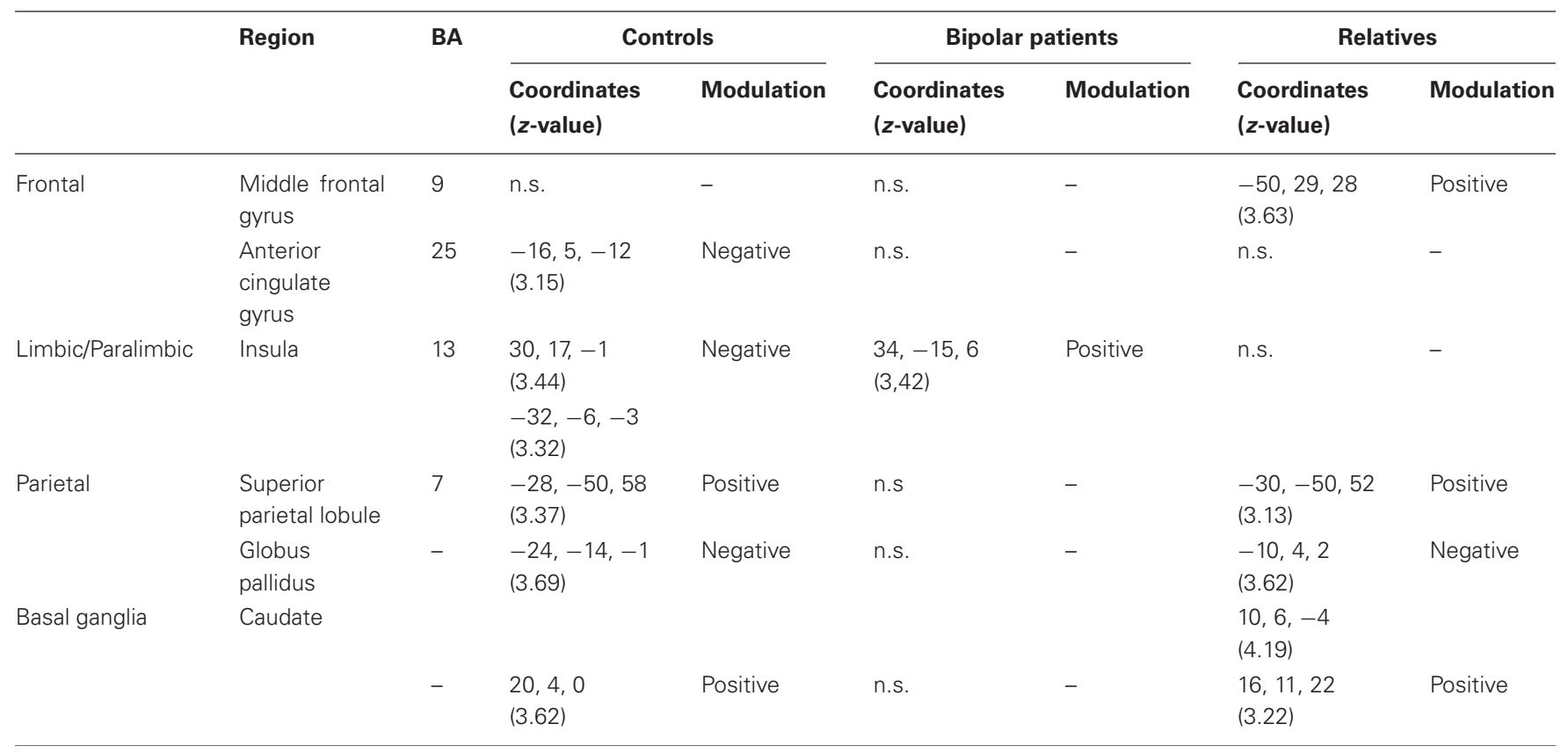

$B A=$ Brodmann Area; coordinates are presented in Talairach and Tournoux space $x=$ sagittal; $y=$ coronal; $z=$ axial; $n . s .=$ not significant at $p<0.001$ voxelwise.

Insula involvement has been shown in a variety of conditions involving the primary and multimodal integrative processing of interoceptive stimuli supporting both a coherent representation and awareness of feelings toward stimuli or events (Craig, 2002, 2011). In this respect increased insular volume in BD may relate to findings of increased conscious emotional reactivity observed in patients (Myin-Germeys et al., 2003) and those at risk for BD (Kwapil et al., 2011). The cerebellar vermis is not known to have direct connections with the insula but it is involved in the integrative processing of somatosensory stimuli (through its connections with the brainstem and thalamus), emotional states (via the amygdala, septum, and locus coeruleus) and motor responses (through its connections with the motor cortex) (Sacchetti et al., 2009). However, unlike the insula, the cerebellum does not influence conscious experience of emotions (Maschke et al., 2002; Turner et al., 2007) but appears to participate in contextual emotional learning and overt behavior through appropriate response selection (Sacchetti et al., 2009). Any extrapolation from these data to BD can only be purely speculative as this point. It could be argued however, that resilient relatives may experience $s u b$ jectively greater emotional fluctuations (associated with insula function) but their objective behavior remains appropriate due to greater control over response selection (associated with vermal function).

\section{FUNCTIONAL CORRELATES OF RESILIENCE IN BD}

Functional activation and connectivity in this study were examined using the SCWT. In healthy individuals the task engages a network of brain structures with evidence of relative regional specialization (Wager et al., 2005; Nee et al., 2007). Within this network, the DLPFC is thought to maintain representations of task-relevant information and to bias activity in other regions toward task-appropriate responses (Milham et al., 2003; Liu et al., 2006; Nee et al., 2007). Selective attention processes operating within posterior parietal regions integrate task relevance and stimulus features into unified representations of "salience" (Buschman and Miller, 2007) or "priority" (Bays et al., 2010) used for competitive stimulus selection. The ACC is involved in monitoring conflict and performance (MacDonald et al., 2000; Milham et al., 2003; Liu et al., 2006; Nee et al., 2007; Pochon et al., 2008). Response execution primarily involves the VLPFC (Aron et al., 2004; Nee et al., 2007) and the striatum (Derrfuss et al., 2005; Chevrier et al., 2007; Nee et al., 2007; Robins et al., 2007; Li et al., 2008; Ali et al., 2010).

During the SCWT patients with BD and their relatives demonstrated quantitatively similar signal reduction in posterior parietal regions. We infer from these results that in even in healthy relatives genetic predisposition to BD disrupts the SCWT network particularly in connection to selective attention processes that are underpinned by the functional integrity of the posterior parietal cortices. Patients showed additional signal decrements in regions involved in response selection and execution, namely the VLPFC and the caudate nucleus, which were not present in relatives.

As BD arises from abnormalities within neural systems, not just regions, we also examined the functional integration of the SCWT network. During tasks of cognitive control, such as the SCWT, activation is increased in task-relevant brain regions and reduced in regions involved in emotional processing (Drevets and Raichle, 1998; Hester et al., 2004; Wager et al., 2005; Margulies et al., 2007). Accordingly, controls showed negative functional coupling between the VLPFC and the vACC and insula. Both regions are known for their primary role in the monitoring and generation of internal affective states (Reiman et al., 1997; Damasio et al., 2000; Dolan, 2002; Phan et al., 2002). Connectivity 
between the VLPFC and these regions was abnormal in patients and relatives, although the degree of deviance was greater in patients. These observations imply that genetic liability to $\mathrm{BD}$ is associated with inefficient resource allocation between cortical and limbic/paralimbic regions. This finding has been reported in a number of studies using different paradigms (Adler et al., 2004; Krüger et al., 2006; Drevets et al., 2008; Thermenos et al., 2010) and is therefore, likely to represent a task-independent feature of BD. Furthermore, insular volume was found to be increased in both patients and relatives in this sample. The results of the connectivity analysis therefore, provide a direct link between structural and functional alterations mediated by genetic predisposition to $\mathrm{BD}$.

A unique feature of the VLPFC connectivity in relatives was its positive coupling with the DLPFC suggestive of reciprocal augmentation in activity of these two regions. During the SCWT engagement of the DLPFC involvement reflects the contribution of this region both in selective attention and response selection (Nee et al., 2007); furthermore, the DLPFC appears to modulate activity in the VLPFC as a function of increased task difficulty (Nee et al., 2007). We, therefore, interpret the increased connectivity between ventral and dorsal lateral PFC in relatives as an adaptive mechanism that allows greater conjunctive activity within the PFC in response to functional dysregulation in other areas of the SCWT network.

\section{METHODOLOGICAL CONSIDERATIONS}

The literature on adaptive responses associated with resilience in relatives of patients with $\mathrm{BD}$ is sparse. The generalizability of our findings would, therefore, require independent replication. However, our results resonate with those of Krüger et al. (2006) who measured regional cerebral blood flow (rCBF) in nine $\mathrm{BD}$ patients and nine healthy siblings after induction of transient sadness. Patients and siblings had overlapping abnormalities in cortical activity during this task but importantly siblings showed increased medial PFC activation that was unique to their group. Furthermore, the functional findings in relatives

\section{REFERENCES}

Adler, C. M., Holland, S. K., Schmithorst, V., Tuchfarber, M. J., and Strakowski, S. M. (2004). Changes in neuronal activation in patients with bipolar disorder during performance of a working memory task. Bipolar Disord. 6, 540-549.

Akiskal, H. S., Maser, J. D., Zeller, P. J., Endicott, J., Coryell, W., Keller, M., Warshaw, M., Clayton, P., and Goodwin, F. (1995). Switching from "unipolar" to bipolar II. An 11year prospective study of clinical and temperamental predictors in 559 patients. Arch. Gen. Psychiatry 52, 114-123.

Ali, N., Green, D. W., Kherif, F., Devlin, J. T., and Price, C. J. (2010). The role of the left head of caudate in suppressing irrelevant words. J. Cogn. Neurosci. 22, 2369-2386.
American Psychiatric Association. (1994). Diagnostic and Statistical Manual of Mental Disorders, 4th Edn. Washington, DC: American Psychiatric Association Press.

Aron, A. R., Robbins, T. W., and Poldrack, R. A. (2004). Inhibition and the right inferior frontal cortex. Trends Cogn. Sci. 8, 170-177.

Arts, B., Jabben, N., Krabbendam, L., and van Os, J. (2008). Metaanalyses of cognitive functioning in euthymic bipolar patients and their first-degree relatives. Psychol. Med. 38, 771-785.

Bays, P. M., Singh-Curry, V., Gorgoraptis, N., Driver, J., and Husain, M. (2010). Integration of goal- and stimulus-related visual signals revealed by damage to human parietal cortex. J. Neurosci. 30, 5968-5978.

during the SCWT did not correlate with measures of performance. This could be attributable to near ceiling performance in the task. Another possibility is that adaptive responses may not have a quantitative association with performance but they act to maintain functional capacity.

\section{IMPLICATIONS AND FUTURE DIRECTIONS}

As discussed adaptive responses within brain networks emerge as a feature of resilience in healthy relatives of $\mathrm{BD}$ patients. Adaptive responses can be conceptualized in terms of neural reserve and neural compensation (Stern, 2002). Neural reserve is thought to represent the ability of brain networks to cope with pathology or higher demands as a function of their increased efficiency or plasticity or recruitment of additional neural resources. Neural compensation refers to reallocation of processing to alternate brain regions. Accordingly, the features associated with resilience in relatives appear indicative of increased reserve since in the SCWT, at least, the architecture of the network involved was similar to controls. However, a more precise formulation of the nature of the adaptive responses associated with resilience will require further studies.

Another issue for further examination is the relationship with disease expression. Clinical symptoms may arise because of failure to develop or maintain adaptive changes in response to genetically-mediated brain pathology. Alternatively, abnormalities in specific brain areas may have a direct pathogenic effect that pre-empts adaptive responses. Longitudinal studies of individuals at high risk for $\mathrm{BD}$ would be informative in this respect.

A third question concerns the causes or sources of adaptive brain responses in resilient relatives. For example, Hunsberger et al. (2009) have proposed several mechanisms that could potentially enhance resilience in $\mathrm{BD}$ that relate to regulation of stress response or apoptotic cascades.

\section{ACKNOWLEDGMENTS}

This research was partially supported by a NARSAD Independent Investigator Award to Dr. Frangou.

Bezchlibnyk-Butler, K., and Jeffries, J. (2000). Clinical Handbook of Psychotropic Drugs, 10th Edn. Toronto, ON: Hogrefe \& Huber.

Blumberg, H. P., Leung, H. C., Skudlarski, P., Lacadie, C. M., Fredericks, C. A., Harris, B. C., Charney, D. S., Gore, J. C., Krystal, J. H., and Peterson, B. S. (2003). A functional magnetic resonance imaging study of bipolar disorder: state- and trait-related dysfunction in ventral prefrontal cortices. Arch. Gen. Psychiatry 60, 601-609.

Bora, E., Yucel, M., and Pantelis, C. (2009). Cognitive endophenotypes of bipolar disorder: a meta-analysis of neuropsychological deficits in euthymic patients and their first-degree relatives. J. Affect. Disord. 113, 1-20.

Buschman, T. J., and Miller, E. K. (2007). Top-down versus bottom-up control of attention in the prefrontal and posterior parietal cortices. Science 315, 1860-1862.

Carpenter, S. R., Walker, B., Anderies, J. M., and Abel, N. (2001). From metaphor to measurement: resilience of what to what? Ecosystems 4, 765-781.

Chen, C. H., Suckling, J., Lennox, B. R., Ooi, C., and Bullmore, E. T. (2011). A quantitative meta-analysis of fMRI studies in bipolar disorder. Bipolar Disord. 13, 1-15.

Chevrier, A. D., Noseworthy, M. D., and Schachar, R. (2007). Dissociation of response inhibition and performance monitoring in the stop signal task using event-related fMRI. Hum. Brain Mapp. 28, 1347-1358.

Coryell, W., Endicott, J., Maser, J. D., Keller, M. B., Leon, A. C., and Akiskal, H. S. (1995). Long-term stability of polarity distinctions 
in the affective disorders. Am. J. Psychiatry 152, 385-390.

Craig, A. D. (2002). How do you feel? Interoception: the sense of the physiological condition of the body. Nat. Rev. Neurosci. 3, 655-666.

Craig, A. D. (2011). Significance of the insula for the evolution of human awareness of feelings from the body. Ann. N.Y. Acad. Sci. 1225, 72-82.

Damasio, A. R., Grabowski, T. J., Bechara, A., Damasio, H., Ponto, L. L., Parvizi, J., and Hichwa, R. D. (2000). Subcortical and cortical brain activity during the feeling of self-generated emotions. Nat. Neurosci. 3, 1049-1056.

Derrfuss, J., Brass, M., Neumann, J., and von Cramon, D. Y. (2005). Involvement of the inferior frontal junction in cognitive control: metaanalyses of switching and Stroop studies. Hum. Brain Mapp. 25, 22-34.

Dolan, R. J. (2002). Emotion, cognition, and behavior. Science 298, 1191-1194.

Drapier, D., Surguladze, S., Marshall, N., Schulze, K., Fern, A., Hall, M. H., Walshe, M., Murray, R. M., and McDonald, C. (2008). Genetic liability for bipolar disorder is characterized by excess frontal activation in response to a working memory task. Biol. Psychiatry 64, 513-520.

Drevets, W. C., and Raichle, M. E. (1998). Reciprocal suppression of regional cerebral blood flow during emotional versus higher cognitive processes: implications for interactions between emotion and cognition. Cogn. Emot. 12, 353-385.

Drevets, W. C., Savitz, J., and Trimble, M. (2008). The subgenual anterior cingulate cortex in mood disorders. CNS Spectr. 13, 663-681.

Ferreira, M. A., O’Donovan, M. C., Meng, Y. A., Jones, I. R., Ruderfer, D. M., Jones, L., Fan, J., Kirov, G., Perlis, R. H., Green, E. K., Smoller, J. W., Grozeva, D., Stone, J., Nikolov, I., Chambert, K., Hamshere, M. L., Nimgaonkar, V. L., Moskvina, V., Thase, M. E., Caesar, S., Sachs, G. S., Franklin, J., Gordon-Smith, K., Ardlie, K. G., Gabriel, S. B., Fraser, C., Blumenstiel, B., Defelice, M., Breen, G., Gill, M., Morris, D. W., Elkin, A., Muir, W. J., McGhee, K. A., Williamson, R., MacIntyre, D. J., MacLean, A. W. St. C. D., Robinson, M., van Beck, M., Pereira, A. C., Kandaswamy, R., McQuillin, A., Collier, D. A., Bass, N. J., Young, A. H., Lawrence, J., Ferrier, I. N., Anjorin, A., Farmer, A., Curtis, D., Scolnick, E. M., McGuffin, P., Daly, M. J., Corvin, A. P., Holmans, P. A., Blackwood, D. H., Gurling, H. M.,
Owen, M. J., Purcell, S. M., Sklar, P., Craddock, N., and Wellcome Trust Case Control Consortium. (2008). Collaborative genome-wide association analysis supports a role for ANK3 and CACNA1C in bipolar disorder. Nat. Genet. 40, 1056-1058.

First, M. B., Gibbon, M., Spitzer, R. L., Williams, J. B. W., and Benjamin, L. S. (1997). Structured Clinical Interview for DSM-IV Axis II Personality Disorders (SCIDII). Washington, DC: American Psychiatric Press.

First, M. B., Spitzer, R. L., Gibbon, M., and Williams, J. B. W. (2002a). Structured Clinical Interview for DSM-IV-TR Axis I Disorders, Research Version, Patient Edn. (SCID-I/P). New York: New York Biometrics Research.

First, M. B., Spitzer, R. L., Gibbon, M., and Williams, J. B. W. (2002b). Structured Clinical Interview for DSM-IV-TR Axis I Disorders, Research Version, Non-Patient Edn. (SCID-I/NP). New York: New York Biometrics Research.

Frangou, S. (2009). Risk and resilience in bipolar disorder: rationale and design of the Vulnerability to Bipolar Disorders Study (VIBES). Biochem. Soc. Trans. 37, 1085-1089.

Friston, K. J., Buechel, C., Fink, G. R., Morris, J., Rolls, E., and Dolan, R. J. (1997). Psychophysiological and modulatory interactions in neuroimaging. Neuroimage 6, 218-229.

Galvez, J. F., Thommi, S., and Ghaemi, S. N. (2011). Positive aspects of mental illness: a review in bipolar disorder. J. Affect. Disord. 128, 185-190.

Glahn, D. C., Almasy, L., Barguil, M., Hare, E., Peralta, J. M., Kent, J. W. Jr., Dassori, A., Contreras, J., Pacheco, A., Lanzagorta, N., Nicolini, H., Raventós, H., and Escamilla, M. A. (2010). Neurocognitive endophenotypes for bipolar disorder identified in multiplex multigenerational families. Arch. Gen. Psychiatry 67, 168-177.

Gruber, S. A., Rogowska, J., and Yurgelun-Todd, D. A. (2004). Decreased activation of the anterior cingulate in bipolar patients: an fMRI study. J. Affect. Disord. 82, 191-201.

Hamilton, M. (1960). A rating scale for depression. J. Neurol. Neurosurg. Psychiatry 23, 56-62.

Hester, R. L., Murphy, K., Foxe, J. J., Foxe, D. M., Javitt, D. C., and Garavan, H. (2004). Predicting success: patterns of cortical activation and deactivation prior to response inhibition. J. Cogn. Neurosci. 16, 776-785.

Hunsberger, J. G., Austin, D. R., Chen, G., and Manji, H. K. (2009). Cellular mechanisms underlying affective resiliency: the role of glucocorticoid receptor- and mitochondriallymediated plasticity. Brain Res. 1293 , 76-84.

Jogia, J., Ruberto, G., Lelli-Chiesa, G., Vassos, E., Maierú, M., Tatarelli, R., Girardi, P., Collier, D., and Frangou, S. (2011). The impact of the CACNA1C gene polymorphism on frontolimbic function in bipolar disorder. Mol. Psychiatry 16, 1070-1071.

Kempton, M. J., Geddes, J. R., Ettinger, U., Williams, S. C., and Grasby, P. M. (2008). Meta-analysis, database, and meta-regression of 98 structural imaging studies in bipolar disorder. Arch. Gen. Psychiatry 65, 1017-1032.

Kempton, M. J., Haldane, M., Jogia, J., Grasby, P. M., Collier, D., and Frangou, S. (2009). Dissociable brain structural changes associated with predisposition, resilience, and disease expression in bipolar disorder. J. Neurosci. 29, 10863-10868.

Kempton, M. J., Salvador, Z., Munafò, M. R., Geddes, J. R., Simmons, A., Frangou, S., and Williams, S. C. (2011). Structural neuroimaging studies in major depressive disorder. Meta-analysis and comparison with bipolar disorder. Arch. Gen. Psychiatry 68, 675-690.

Kronhaus, D. M., Lawrence, N. S., Williams, A. M., Frangou, S., Brammer, M. J., Williams, S. C. Andrew, C. M., and Phillips, M. L. (2006). Stroop performance in bipolar disorder: further evidence for abnormalities in the ventral prefrontal cortex. Bipolar Disord. 8, 28-39.

Krüger, S., Alda, M., Young, L. T., Goldapple, K., Parikh, S., and Mayberg, H. S. (2006). Risk and resilience markers in bipolar disorder: brain responses to emotional challenge in bipolar patients and their healthy siblings. Am. J. Psychiatry 163, 257-264.

Kwapil, T. R., Barrantes-Vidal, N., Armistead, M. S., Hope, G. A., Brown, L. H., Silvia, P. J., and MyinGermeys, I. (2011). The expression of bipolar spectrum psychopathology in daily life. J. Affect. Disord. 130, 166-170.

Lagopoulos, J., and Malhi, G. S. (2007). A functional magnetic resonance imaging study of emotional Stroop in euthymic bipolar disorder. Neuroreport 18, 1583-1587.
Lelli-Chiesa, G., Kempton, M. J., Jogia, J., Tatarelli, R., Girardi, P., Powell, J., Collier, D. A., and Frangou, S. (2011). The impact of the Val158Met catechol- Omethyltransferase genotype on neural correlates of sad facial affect processing in patients with bipolar disorder and their relatives. Psychol. Med. 41, 779-788.

Li, C. S., Yan, P., Sinha, R., and Lee, T. W. (2008). Subcortical processes of motor response inhibition during a stop signal task. Neuroimage 41, 1352-1363.

Lichtenstein, P., Yip, B. H., Björk, C., Pawitan, Y., Cannon, T. D., Sullivan, P. F., and Hultman, C. M. (2009). Common genetic determinants of schizophrenia and bipolar disorder in Swedish families: a population-based study. Lancet 373, 234-239.

Liu, X., Banich, M. T., Jacobson, B. L., and Tanabe, J. L. (2006). Functional dissociation of attentional selection within PFC: response and non-response related aspects of attentional selection as ascertained by fMRI. Cereb. Cortex 16, 827-834.

Lukoff, D., Nuechterlien, K., and Ventura, J. (1986). Manual for the expanded Brief Psychiatric Rating Scale. Schizophr. Bull. 12, 594-608.

MacDonald, A. W. 3rd, Cohen, J. D., Stenger, V. A., and Carter, C. S. (2000). Dissociating the role of the dorsolateral prefrontal and anterior cingulate cortex in cognitive control. Science 288, 1835-1838.

Maldjian, J. A., Laurienti, P. J., Kraft, R. A., and Burdette, J. H. (2003). An automated method for neuroanatomic and cytoarchitectonic atlas-based interrogation of fMRI data sets. Neuroimage 19, 1233-1239.

Malhi, G. S., Lagopoulos, J., Sachdev, P. S., Ivanovski, B., and Shnier, R. (2005). An emotional Stroop functional MRI study of euthymic bipolar disorder. Bipolar Disord. 7 (Suppl. 5), 58-69.

Margulies, D. S., Kelly, A. M., Uddin, L. Q., Biswal, B. B., Castellanos, F. X., and Milham, M. P. (2007). Mapping the functional connectivity of anterior cingulate cortex. Neuroimage 37, 579-588.

Maschke, M., Schugens, M., Kindsvater, K., Drepper, J., Kolb, F. P., Diener, H. C., Daum, I., and Timmann, D. (2002). Fear conditioned changes of heart rate in patients with medial cerebellar lesions. J. Neurol. Neurosurg. Psychiatry 72, 116-118. 
Maxwell, E. (1992). The Family Interview for Genetic Studies Manual. National Institute of Mental Health. Washington, DC: Pearson.

McDonald, C., Bullmore, E. T., Sham, P. C., Chitnis, X., Wickham, H., Bramon, E., and Murray, R. M. (2004). Association of genetic risks for schizophrenia and bipolar disorder with specific and generic brain structural endophenotypes. Arch. Gen. Psychiatry 61, 974-984.

McGuffin, P., Rijsdijk, F., Andrew, M., Sham, P., Katz, R., and Cardno, A. (2003). The heritability of bipolar affective disorder and the genetic relationship to unipolar depression. Arch. Gen. Psychiatry 60, 497-502.

McIntosh, A. M., Job, D. E., Moorhead, T. W., Harrison, L. K., Forrester, K., Lawrie, S. M., and Johnstone, E. C. (2004). Voxel-based morphometry of patients with schizophrenia or bipolar disorder and their unaffected relatives. Biol. Psychiatry 56, 544-552.

Merikangas, K. R., Jin, R., He, J. P., Kessler, R. C., Lee, S., Sampson, N. A., Viana, M. C., Andrade, L. H., Hu, C., Karam, E. G., Ladea, M., MedinaMora, M. E., Ono, Y., Posada-Villa, J., Sagar, R., Wells, J. E., and Zarkov, Z. (2011). Prevalence and correlates of bipolar spectrum disorder in the world mental health survey initiative. Arch. Gen. Psychiatry 68, 241-251.

Milham, M. P., Banich, M. T., and Barad, V. (2003). Competition for priority in processing increases prefrontal cortex's involvement in top-down control: an event-related fMRI study of the Stroop task. Brain Res. Cogn. Brain Res. 17, 212-222.

Mowbray, C. T., Bybee, D., Oyserman, D., MacFarlane, P., and Bowersox, N. (2006). Psychosocial outcomes for adult children of parents with severe mental illnesses: demographic and clinical history predictors. Health Soc. Work 31, 99-108.

Myin-Germeys, I., Peeters, F., Havermans, R., Nicolson, N. A., DeVries, M. W., Delespaul, P., and van Os, J. (2003). Emotional reactivity to daily life stress in psychosis and affective disorder: an experience sampling study. Acta Psychiatr. Scand. 107, 124-131.

Nee, D. E., Wager, T. D., and Jonides, J. (2007). Interference resolution: insights from a meta-analysis of neuroimaging tasks. Cogn. Affect. Behav. Neurosci. 7, 1-17.
Parsons, L. M., Denton, D., Egan, G., McKinley, M., Shade, R., Lancaster, J., and Fox, P. T. (2000). Neuroimaging evidence implicating cerebellum in support of sensory/cognitive processes associated with thirst. Proc. Natl. Acad. Sci. U.S.A. 97, 2332-2336.

Pavuluri, M. N., O'Connor, M. M., Harral, E. M., and Sweeney, J. A. (2008). An fMRI study of the interface between affective and cognitive neural circuitry in pediatric bipolar disorder. Psychiatry Res. 162 244-255.

Perrier, E., Pompei, F., Ruberto, G., Vassos, E., Collier, D., and Frangou, S. (2011). Initial evidence for the role of CACNA1C on subcortical brain morphology in patients with bipolar disorder. Eur. Psychiatry 26, 135-1357.

Phan, K. L., Wager, T., Taylor, S. F., and Liberzon, I. (2002). Functional neuroanatomy of emotion: a metaanalysis of emotion activation studies in PET and fMRI. Neuroimage $16,331-348$.

Phillips, M. L., Ladouceur, C. D., and Drevets, W. C. (2008). A neural model of voluntary and automatic emotion regulation: implications for understanding the pathophysiology and neurodevelopment of bipolar disorder. Mol. Psychiatry 13, 829-857.

Pochon, J. B., Riis, J., Sanfey, A. G., Nystrom, L. E., and Cohen, J. D. (2008). Functional imaging of decision conflict. J. Neurosci. 28, 3468-3473.

Pompei, F., Jigar, J., Tatarelli, R., Girardi, P., Rubia, K., Kumari, V., and Frangou, S. (2011a) Familial and disease specific abnormalities in the neural correlates of the Stroop Task in Bipolar Disorder. Neuroimage 56, 1677-1684.

Pompei, F., Dima, D., Rubia, K., Kumari, V., Frangou, S. (2011b). Dissociable functional connectivity changes during the Stroop task relating to risk, resilience and disease expression in bipolar disorder. Neuroimage 57, 576-582.

Ramnani, N. (2006). The primate cortico-cerebellar system: anatomy and function. Nat. Rev. Neurosci. 7, 511-522.

Reiman, E. M., Lane, R. D., Ahern, G. L., Schwartz, G. E., Davidson, R. J, Friston, K. J., Yun, L. S., and Chen, K. (1997). Neuroanatomical correlates of externally and internally generated human emotion. Am. J. Psychiatry 154, 918-925.

Reis, D. J., and Golanov, E. V. (1997). Autonomic and vasomotor regulation. Int. Rev. Neurobiol. 41, 121-149.

Robins, T. W. (2007). Shifting and stopping: fronto-striatal substrates, neurochemical modulation and clinical implications. Philos. Trans. R. Soc. Lond. B Biol. Sci. 362, 917-932.

Roth, R. M., Koven, N. S., Randolph, J. J., Flashman, L. A., Pixley, H. S., Ricketts, S. M., Wishart, H. A., and Saykin, A. J. (2006) Functional magnetic resonance imaging of executive control in bipolar disorder. Neuroreport 17, 1085-1089.

Sacchetti, B., Scelfo, B., and Strata, P. (2009). Cerebellum and emotional behavior. Neuroscience 162 756-762.

Schmahmann, J. D. (2004). Disorders of the cerebellum: ataxia, dysmetria of thought, and the cerebellar cognitive affective syndrome. $J$. Neuropsychiatry Clin. Neurosci. 16, 367-378.

Schmahmann, J. D., and Caplan, D. (2006). Cognition, emotion and the cerebellum. Brain 129, 290-292.

Schmahmann, J. D., and Sherman, J. C. (1998). The cerebellar cognitive affective syndrome. Brain 121 561-579.

Singer, T., Seymour, B., O’Doherty, J., Kaube, H., Dolan, R. J., and Frith, C. D. (2004). Empathy for pain involves the affective but not sensory components of pain. Science 303, 1157-1162.

Sklar, P., Ripke, S., Scott, L. J., Andreassen, O. A., Cichon, S. Craddock, N., Edenberg, H. J., Nurnberger, J. I. Jr., Rietschel, M., Blackwood, D., Corvin, A., Flickinger, M., Guan, W. Mattingsdal, M., McQuillin, A. Kwan, P., Wienker, T. F., Daly, M. Dudbridge, F., Holmans, P. A., Lin, D., Burmeister, M., Greenwood, T. A., Hamshere, M. L., Muglia, P. Smith, E. N., Zandi, P. P., Nievergelt, C. M., McKinney, R., Shilling, P. D. Schork, N. J., Bloss, C. S., Foroud, T., Koller, D. L., Gershon, E. S. Liu, C., Badner, J. A., Scheftner W. A., Lawson, W. B., Nwulia, E. A., Hipolito, M., Coryell, W. Rice, J., Byerley, W., McMahon, F. J., Schulze, T. G., Berrettini, W. Lohoff, F. W., Potash, J. B., Mahon, P. B., McInnis, M. G., Zöllner, S. Zhang, P., Craig, D. W., Szelinger, S., Barrett, T. B., Breuer, R., Meier S., Strohmaier, J., Witt, S. H., Tozzi, F., Farmer, A., McGuffin, P., Strauss, J., Xu, W., Kennedy, J. L., Vincent, J. B., Matthews, K., Day, R., Ferreira, M. A., O’Dushlaine, C., Perlis, R., Raychaudhuri, S.,
Ruderfer, D., Hyoun, P. L., Smoller, J. W., Li, J., Absher, D., Thompson, R. C., Meng, F. G., Schatzberg, A. F., Bunney, W. E., Barchas, J. D., Jones, E. G., Watson, S. J., Myers, R. M., Akil, H., Boehnke, M., Chambert, K., Moran, J., Scolnick, E., Djurovic, S., Melle, I., Morken, G., Gill, M., Morris, D., Quinn, E., Mühleisen, T. W., Degenhardt, F. A., Mattheisen, M., Schumacher, J., Maier, W., Steffens, M., Propping, P., Nöthen, M. M., Anjorin, A. Bass, N., Gurling, H., Kandaswamy, R., Lawrence, J., McGhee, K., McIntosh, A., McLean, A. W., Muir, W. J., Pickard, B. S., Breen, G., St. Clair, D., Caesar, S., Gordon-Smith, K., Jones, L., Fraser, C., Green, E. K., Grozeva, D., Jones, I. R., Kirov, G., Moskvina, V., Nikolov, I., O’Donovan, M. C., Owen, M. J., Collier, D. A., Elkin, A., Williamson, R., Young, A. H., Ferrier, I. N., Stefansson, K., Stefansson, H., Thornorgeirsson, T., Steinberg, S., Gustafsson, O., Bergen, S. E., Nimgaonkar, V., Hultman, C., Landén, M., Lichtenstein, P. Sullivan, P., Schalling, M., Osby, U., Backlund, L., Frisén, L., Langstrom, N., Jamain, S., Leboyer, M., Etain, B., Bellivier, F., Petursson, H., Sigursson, E., Müller-Mysok, B., Lucae, S., Schwarz, M., Schofield, P. R., Martin, N., Montgomery, G. W., Lathrop, M., Oskarsson, H., Bauer, M., Wright, A., Mitchell, P. B., Hautzinger, M., Reif, A., Kelsoe, J. R., Purcell, S. M., and Psychiatric GWAS Consortium Bipolar Disorder Working Group. (2011). Large-scale genome-wide association analysis of bipolar disorder identifies a new susceptibility locus near ODZ4. Nat. Genet. 43, 977-983.

Smoller, J. W., and Finn, C. T. (2003). Family, twin, and adoption studies of bipolar disorder. Am. J. Med. Genet. C Semin. Med. Genet. 123C, $48-58$.

Stefanopoulou, E., Manoharan, A., Landau, S., Geddes, J. R. Goodwin, G., and Frangou, S. (2009). Cognitive functioning in patients with affective disorders and schizophrenia: a meta-analysis. Int Rev. Psychiatry 21, 336-356.

Stern, Y. (2002). What is cognitive reserve? Theory and research application of the reserve concept. J. Int. Neuropsychol. Soc. 8, 448-460.

Stoodley, C. J., and Schmahmann, J. D. (2009). Functional topography in the human cerebellum: a metaanalysis of neuroimaging studies. Neuroimage 44, 489-501. 
Stoodley, C. J., and Schmahmann, J. D. (2010). Evidence for topographic organization in the cerebellum of motor control versus cognitive and affective processing. Cortex 46, 831-844.

Strakowski, S. M., Adler, C. M., Holland, S. K., Mills, N. P., DelBello, M. P., and Eliassen, J. C. (2005). Abnormal FMRI brain activation in euthymic bipolar disorder patients during a counting Stroop interference task. Am. J. Psychiatry 162, 1697-1705.

Stroop, J. R. (1935). Studies of interference in serial verbal reactions. J. Exp. Psychol. XVIII, 643-662.

Takahashi, T., Walterfang, M., Wood, S. J., Kempton, M. J., Jogia, J., Lorenzetti, V., Soulsby, B., Suzuki, M., Velakoulis, D., Pantelis, C., and Frangou, S. (2010). Pituitary volume in patients with bipolar disorder and their first-degree relatives. J. Affect. Disord. 124, 256-261.

Thermenos, H. W., Goldstein, J. M., Milanovic, S. M., Whitfield-Gabrieli, S., Makris, N., Laviolette, P., Koch, J. K., Faraone, S. V., Tsuang, M. T., Buka, S. L., and Seidman, L. J. (2010). An fMRI study of working memory in persons with bipolar disorder or at genetic risk for bipolar disorder. Am. J. Med. Genet. B Neuropsychiatr. Genet. 153B, 120-131.

Thirion, B., Pinel, P., Meriaux, S., Roche, A., Dehaene, S., and Poline, J. B. (2007). Analysis of a large fMRI cohort: statistical and methodological issues for group analyses. Neuroimage 35, 105-120.

Turner, B. M., Paradiso, S., Marvel, C. L., Pierson, R., Boles Ponto, L. L., Hichwa, R. D., and Robinson, R. G. (2007). The cerebellum and emotional experience. Neuropsychologia $45,1331-1341$.
Wager, T. D., Sylvester, C. Y., Lacey, S. C., Nee, D. E., Franklin, M., and Jonides, J. (2005). Common and unique components of response inhibition revealed by fMRI. Neuroimage 27, 323-340.

Walterfang, M., Wood, A. G., Barton, S., Velakoulis, D., Chen, J., Reutens, D. C., Kempton, M. J., Haldane, M., Pantelis, C., and Frangou, S. (2009). Corpus callosum size and shape alterations in individuals with bipolar disorder and their first-degree relatives. Prog. Neuropsychopharmacol. Biol. Psychiatry 33, 1050-1057.

Wechsler, D. (1997). Wechsler Adult Intelligence Scale, 3rd Edn. San Antonio: Pearson.

Young, R. C., Biggs, J. T., Ziegler, V. E. and Meyer, D. A. (1978). A rating scale for mania: reliability, validity and sensitivity. Br. J. Psychiatry 133 , 429-435.
Conflict of Interest Statement: The author declares that the research was conducted in the absence of any commercial or financial relationships that could be construed as a potential conflict of interest.

Received: 02 December 2011; paper pending published: 06 December 2011; accepted: 21 December 2011; published online: 27 January 2012.

Citation: Frangou S (2012) Brain structural and functional correlates of resilience to Bipolar Disorder. Front. Hum. Neurosci. 5:184. doi: 10.3389/ fnhum.2011.00184

Copyright (c) 2012 Frangou. This is an open-access article distributed under the terms of the Creative Commons Attribution Non Commercial License, which permits non-commercial use, distribution, and reproduction in other forums, provided the original authors and source are credited. 